\title{
"Public communication science in times of the Covid-19 crisis": DACH 21 preconference
}

Silke Fürst, University of Zurich, Department of Communication and Media Research IKMZ, Switzerland

s.fuerst@ikmz.uzh.ch

What is public science? What can communication science scholars contribute to society, especially in times of crisis? What are the challenges and limitations of such engagement? These questions were addressed at a recent preconference held on April 7, 2021, titled "Public communication science in times of the Covid-19 crisis". The preconference was organized as part of the DACH 21 conference (the first three-country conference on communication science) and was held online with more than 50 participants. It was an excellent opportunity to stimulate discussion among Swiss, Austrian, and German scholars regarding the self-understanding and societal role of the discipline. The preconference was hosted by the association Öffentliche Medien- und Kommunikationswissenschaft (Public Media and Communication Science, PMCS), which aims to establish, promote, and further develop the concept of public science in the field. ${ }^{1}$

The co-presidents of the PMCS association, Prof. Dr. Marlis Prinzing (Hochschule Macromedia Köln) and Prof. Dr. Mark Eisenegger (University of Zurich), welcomed all participants to the preconference. They emphasized that the preconference aimed to bring together diverse perspectives and to reflect on principles as laid out in the charter of the association (https://oeffentliche-kowi.org/charta/). This charter consists of fifteen principles and was signed by more than 250 scholars.

1 For more information, see the website of Öffentliche Medien- und Kommunikationswissenschaft: https://oeffentliche-kowi.org/ ueber-uns/. The author of this report is a founding and board member of the PMCS association.

\section{What is public science?}

The preconference opened with a talk on the topic "What is public science?" by Prof. Dr. Caroline Robertson-von Trotha, sociologist, emeritus director of the Zentrum für Angewandte Kulturwissenschaft und Studium Generale am Karlsruher Institut für Technologie (KIT), and board member of the PMCS association. Robertson-von Trotha established the concept of "public science" in the German-speaking area of the field (see, e.g., Robertson-von Trotha \& Muñoz Morcillo, 2012, 2018). In her presentation, she gave a brief historical overview of the emergence and development of public science since the 1980s. In particular, she focused on three milestones that stimulated the concept and practice of public science: the Bodmer Report published by The Royal Society in 1985; the OECD symposium "Promoting public understanding of science and technology", held in 1996; and the UNESCO "World conference on science for the twenty-first century" in 1999. All events highlighted the importance of scientific knowledge and stressed the need to strengthen the communication of such knowledge to and with the public, in order to foster democracy, address the pressing problems of the times, and legitimize science itself.

Over time, the idea that the public and citizens have a right to be involved in information and dialogues about science became increasingly dominant. Allowing citizens' participation and addressing social and global problems was increasingly considered as a responsibility of sciences in general, including the humanities and the social sciences. Robertson-von Trotha emphasized the "participatory turn" in public science that took shape before the 
widespread diffusion of the Internet. However, digitization brought new opportunities and challenges for participation in science, such as more and new communication and information channels that might broaden participation but also lower standards of accuracy and transparency. Moreover, she conceptualized the idea of public science as distinct from public relations efforts often conducted by universities or science journals. Accordingly, public science is not about strategic communication but rather about producing and mediating scientific knowledge that is useful for citizens and society, stimulating a critical reception of science, and valuing feedback from diverse publics.

In Robertson-von Trotha's view, this idea of public science can only be fully realized if the reputation mechanisms in science itself value scientists' engagement in public science (see charter, \$14). In many disciplines, however, this is not the case; so far, such engagement most often does not benefit a career in science. Changing these reputation mechanisms is important, especially in light of the diverse forms of science communication that are needed to enable citizens' participation and to mediate knowledge that is crucial for society. The Covid-19 pandemic has shown the pressing need for a constant exchange between science and diverse publics one that could not be sufficiently realized under the current conditions, especially since many disciplines were largely absent from discussions and public discourses.

\section{Expectations of and from science during the Covid-19 pandemic}

After the talk by Robertson-von Trotha, two speakers took on the topic of Covid-19 from different perspectives and outlined expectations of and from science. First, Beat Glogger offered a critical reflection on the role and the communication of science during the pandemic, stating that science still has to learn that both the pandemic and politics are a "marathon". Glogger is a natural scientist, science journalist, and founder of the online science maga- zine higgs.ch. In his talk, he focused on how science and scientists in Switzerland largely disappointed the expectations held by journalists and the public. Glogger observed that Swiss scientists were very visible and active in public discourse at the beginning of the pandemic; later on, however, they "ran out of steam". Many scientists underestimated the duration of the pandemic and the need for steady, regular communication and discussion of scientific findings and uncertainties. Some scientists dropped out of the public eye after being criticized for their communication of pandemic scenarios. Others, such as scientists in the Swiss National Covid-19 Science Task Force, including its former head Prof. Dr. Matthias Egger, withdrew from their positions and from public discussion without giving reasons for doing so. Few scientists are left who communicate accurately and regularly. Moreover, journalists also prominently give a voice to scientists who seek to provoke and polarize discussions. Overall, Glogger felt that during the Covid-19 pandemic, the voice of science as a solid knowledge provider was missing i. e., the regular mediation and discussion of up-to-date knowledge and scientific uncertainties in order to be able to handle the enormous problems and challenges of the pandemic (see charter, $\S 5, \S 7$ ). This is even more crucial in light of increases in disinformation, conspiracy narratives, polarization, and hate speech. Vaccine skeptics and Covid deniers spread disinformation widely, also with the help of so-called "social bots" (see, e.g., Broniatowski et al., 2018).

Beat Glogger drew three conclusions from his observations. First, it is essential to ensure that public discourse around scientific issues is based on scientific evidence (see charter, $\$ 4$ ). Not only the quality but also the quantity and reach of communication is important. As one solution, social bots could be used to disseminate scientific evidence, thereby fighting disinformation bots with information bots. Second, the public is searching for reliable information and needs journalism, as recently illustrated by an increased demand for news on the coronavirus crisis. There- 
fore, the Covid-19 pandemic is not only a challenge but also an opportunity for journalism to demonstrate and maintain its societal importance and its role in the daily lives of users. Third, science must look for partners who understand the business and practices of news media. Glogger considered his online science magazine higgs.ch as such a partner but also generally highlighted the need for infrastructures that enable independent science journalism. Instead of putting more and more resources into the public relations of universities as is currently the case (Vogler \& Schäfer, 2020), it is important to financially support those actors who mediate scientific knowledge in an independent and critical way. Glogger here referenced communication scholar Otfried Jarren, who made clear that while university communication of knowledge is important, it produces self-representations and self-references, while journalism - with its distinct selection and presentation criteria - provides external references (Fremdreferenz) that are necessary for public discourse (see, e.g., Jarren, 2019). Since resources for science journalism are dwindling in Switzerland as well as in many other countries (Kristiansen, Schäfer, \& Lorencez, 2016), Glogger suggested building a foundation that is supported and financed by numerous stakeholders, including the public sector, corporations, private actors, and universities. This foundation would enable the financing of independent production and dissemination of reports on science and scientific knowledge.

Prof. Dr. Matthias Egger contributed to this discussion by shedding light on what science expects from itself as well as from society. Egger is an epidemiologist at the University of Bern and the president of the SNSF National Research Council. Moreover, he was head of the Swiss National Covid-19 Science Task Force, which advises public authorities. From his perspective, the public communication of science during the first months of the Covid-19 pandemic did not have as great an impact as Glogger has observed. Scientists, including Egger himself, were proactive in setting up a Covid-19 Science
Task Force in April 2020; however, the influence of this task force on political decisions was rather low. For the relationship among science, politics, and the public to be fruitful, it is crucial that all participants are engaged, interested, and open-minded. The concept of public science can only become a reality when scientists are willing to engage with different actors from society and when these other actors are interested in hearing and discussing the expertise offered by science and scientists.

As Glogger stated, Matthias Egger withdrew from his position as head of the task force without publicly communicating his reasons; however, the withdrawal was necessary, due to a role conflict. As head of the task force, it is very important to take a prominent place in public discourse and invest time. It is not possible to do this when also holding the position of president of the SNSF National Research Council. As to his experience in the latter, Egger expressed concern about a potential "Covidization of research" (Pai, 2020). We must prevent every scientist from now on thinking that it is their duty to conduct Covid-19-related research. For one thing, only some scientists work in research areas that offer the expertise to carry out studies that help society deal with the pandemic; for another thing, a wide range of pressing problems in science and society that are not related to the Covid-19 pandemic still exist, and it is crucial for such research to continue to be conducted. A "Covidization of research" would not improve research and public science but instead would create "instant experts", reflecting the increasing influence of third-party funding and the growing opportunism among scientists to select research questions and topics according to the likelihood of receiving money.

In Egger's view, scientists should not become activists. They best carry out their specific role in society when they conduct research according to scientific norms and standards and then communicate and discuss the findings, implications, and uncertainties of their research with relevant actors in society. The communication of scientific uncertainty, the critical discus- 
sion of scientific evidence, and the countering of disinformation are key for public science (see charter, $\$ 5$ ).

\section{Communication research on Covid-19 coverage and its public response}

In the last speaker slot, communication and media scholars from Germany, Austria, and Switzerland talked about the public response to their research. Together with their colleagues, Prof. Dr. Thorsten Quandt (University of Münster), Prof. Dr. Josef Trappel (University of Salzburg, board member of the PMCS association), and Dr. Linards Udris (University of Zurich) examined the role of news media in the Covid-19 crisis.

Thorsten Quandt and his colleagues were some of the first to publish research on this issue. In the early months of 2020 , they observed a flourishing of opinions regarding the news media coverage of Covid-19, when facts and data were largely absent. This gave rise to a study that addressed this topic and analyzed a broad sample of German news media and alternative news media through computational content analysis. The project started in March 2020 and was quite intense; white papers were already published in April and May 2020 (Boberg, Quandt, Schatto-Eckrodt, \& Frischlich, 2020; Quandt, Boberg, Schatto-Eckrodt, \& Frischlich, 2020). For instance, the researchers found that the coverage of established news media provided a broad range of positions and concerns but was considerably less negative in tone than articles in alternative news media, which disseminated overly critical messages and opinions. The study attracted a large response from news organizations around the world, including The Washington Post and CNN. Large parts of the coverage were neutral, but there were also critical reports with inaccurate statements about the study, providing Covid deniers and conspiracy believers with rhetorical material for personal attacks on the authors. Consequently, Quandt argued that public science comes with opportuni- ties and challenges. Especially in democracies, science has a duty to serve society and to communicate important findings to concerned publics. This communication contributes to the social impact of science. However, scholars must keep in mind that studies addressing urgent societal problems can entail great stress, due to the need to ensure high scientific quality while working under significant time pressure. Such studies also tend to provoke more public response and potentially personal attacks on researchers. The latter are a particular challenge, considering that many higher education institutions lack structures of support or resources to protect and advise their researchers in such cases. In general, incentives to engage in public science are lacking, resulting in the current, rather insufficient fulfillment of public science.

From an Austrian perspective, Josef Trappel supported these observations. He is the head of an international research group that is conducting a longitudinal analysis of media performance in $18 \mathrm{de}$ mocracies around the globe and ongoing changes in media systems. In September 2020, the researchers presented their latest findings, which shed light on the role of news media during the Covid-19 crisis and the changes in newsrooms and media policies due to the pandemic. "The Media for Democracy Monitor" (2020a, 2020b) showed a significant increase in news usage and trust in news media, while media organizations experienced drastic cuts in advertising revenues at the same time. With this loss of resources, the media performance in many countries is decreasing at a time when disinformation is flourishing and accurate information and critical contextualization of knowledge is needed more than ever. These developments instigated media policies to reconsider direct subsidies for media organizations, in some countries in return for providing space for public advertising campaigns. Ahead of the presentation of the results of this cross-national research project in April 2021, extracts of specific findings were communicated via three press releases and attracted broad media interest; 
news media in the 18 participating countries reported on the research results, most of them in a neutral tone. In contrast to what Thorsten Quandt and his colleagues experienced, no heated controversies or personal attacks arose.

Finally, Linards Udris provided insights into Swiss research on the role of news media during the Covid-19 pandemic. Most recently, scholars have shown that media and communication research rarely contributes to public debates and the broad dissemination of knowledge (Fürst, Vogler, Sörensen, Schäfer, \& Eisenegger, 2020; Nielsen, 2020). However, the work of the Forschungszentrum Öffentlichkeit und Gesellschaft (fög) of the University of Zurich is dedicated to analyzing socially relevant problems and communicating their findings to diverse publics and the news media (see, e.g., fög, 2020). At the beginning of the corona crisis, the fög received several media requests - quicker than it could actually conduct studies and provide scientific findings. However, a few months later, the fög was able to publish studies that received a substantial response in news media and on social media (Eisenegger, Oehmer, Udris, \& Vogler, 2020; Rauchfleisch, Vogler, \& Eisenegger, 2020). Their findings indicated that traditional opinion leaders, such as leading news media and journalists, also influence debates on Twitter to a large extent. Moreover, news coverage in the Swiss media was highly dominated by reports on the Covid-19 pandemic. The fög found a generally high quality of the Covid-19 news media coverage but also identified certain deficiencies, such as common lack of contextualization of issues, data, and scientific findings. Linards Udris concluded that public science is indispensable for society; that scientists have a duty to produce and publicly provide knowledge and empirical evidence; and that public science requires courage, time, and resources. Moreover, Udris argued that public science needs to follow certain rules, as laid out in the charter mentioned above.

All three scholars who shortly presented research projects from DACH countries aimed to address urgent societal problems and questions. They publicly communicated their research findings as promptly as possible in order to inform debates on news quality, dissemination of disinformation, and media policy measures (see charter, preamble, $\S 11$ ), and they received broad public interest.

\section{Discussion}

The discussion with all participants of the preconference first focused on questions of complexity, accuracy, and comprehensibility. Mark Eisenegger and Linards Udris emphasized that research projects aiming to address urgent social problems need to be conducted in a timely manner; however, it is even more important that such studies have a high scientific quality and generate sound evidence. Dr. Katharina Hajek (University of Koblenz · Landau) asked whether we should communicate complex knowledge and insist on using accurate and precise terms, or if this would hinder the attention paid to science and the communication of knowledge altogether. For instance, scientists could contribute to the use of accurate terms in public discourse, such as "conspiracy myths" or "conspiracy narratives" (instead of "conspiracy theories") and "variant B.1.1.7" (instead of "British mutant"), thereby reducing the dissemination of misleading ideas. Generally, Beat Glogger thought this is a good idea; however, at the beginning of an emergent problem or topic, one cannot aim for accuracy and completeness of all terms and their definitions. During this phase, he argued, it is more important to publicly communicate basic insights into a phenomenon instead of provoking information overload or disinterest.

While the preconference mainly focused on communicating empirical findings, Prof. Dr. Klaus Meier (Katholische Universität Eichstätt-Ingolstadt) raised the question of how scholars should deal with normative questions and discussions. Mark Eisenegger agreed that this is an important part of public communication science. Certain norms and perspectives no longer need to be argued about, such as 
the importance of human rights, freedom of speech, and democratic participation. Communication scholars must defend and strengthen these values, rights, and norms. Moreover, they can take normative positions and communicate normative evidence derived from the field of communication and media ethics (see charter, $\$ 4$ ).

Additionally, the participants were interested in how scientists can and should deal with public criticism as well as personal attacks. Matthias Egger said that intense public criticism can be indeed upsetting and could endanger mental health. Therefore, it is important to retain one's composure and to focus on other activities, including leisure time for physical activity. Beat Glogger stated that resilience comes not only from getting used to criticism but also from avoiding reading too much of it. For instance, it is unnecessary to read all the comments on social media, especially when they include lots of hate speech. Furthermore, it helps to get support from others or to put one's energy into preparing well for public appearances and statements. In terms of supportive structures, Thorsten Quandt observed that universities and colleges are often unable to cope with hate speech and personal insults and need to do more to protect and support their employees. Moreover, researchers should intensify discussion about these issues, share experiences, develop strategies for coping with public criticism and incivility, and support one another. The PMCS association has already taken on this issue, as it organized a workshop on "Communication science under public pressure" in November 2020. Marlis Prinzing said that follow-ups will ensue, with the aim of developing guidelines.

As to the status quo of public communication science, Thorsten Quandt argued that the diverse inputs of the preconference have shown a public interest in communication and media research. Thus, the problem is not that "No one cares what we know" (Nielsen, 2018), but rather that we need to take initiative and that we should not expect journalists to knock on our doors. This engagement is very important for the discipline's social impact and contribution to society, although is hardly beneficial for the individual career, as Quandt and Robertson-von Trotha agreed. Careers still largely depend on the impact factor and the quantity of journal articles. Matthias Egger made very similar observations. Many scientists in Switzerland do not take the time to publicly communicate their findings but rather quickly move on to work on their next research proposal, in order to receive funding for a new project and publish journal articles. This is why, generally, only few proposals are seen for "Agora" projects, which are funded by the SNSF to stimulate dialogue between science and society (https://tinyurl.com/ SNSF-Agora). Josef Trappel wondered whether scientists are sometimes motivated but lack the skills to communicate their research findings in sophisticated ways, such as informative movies. In general, however, he agreed that many people talk about the "third mission" of science and universities, despite the fact that in practice this engagement is rarely considered in the evaluation of scientists. Instead of complaining about it, we should contribute to changing these rules: As Trappel put it, it is also up to us to consider public engagement when it comes to evaluating scientists and scientific work. Overall, the preconference highlighted the importance of and need for further exchange on issues of public communication science.

\section{References}

Boberg, S., Quandt, T., Schatto-Eckrodt, T., \& Frischlich, L. (2020). Pandemic populism: Facebook pages of alternative news media and the corona crisis - A computational content analysis. Retrieved from https:// arxiv.org/abs/2004.02566

Broniatowski, D. A., Jamison, A. M., Qi, S., AlKulaib, L., Chen, T., Benton, A., ... Dredze, M. (2018). Weaponized health communication: Twitter bots and russian trolls amplify the vaccine debate. American Journal of Public Health (AJPH), 108(10), 1378-1384. https://www.doi. org/10.2105/AJPH.2018.304567 
Eisenegger, M., Oehmer, F., Udris, L., \& Vogler, D. (2020). Die Qualität der Medienberichterstattung zur Corona-Pandemie. Retrieved from https://www.foeg.uzh.ch/ de/news/analyse-zur-corona-berichterstattung-in-den-schweizer-medien.html

fög (Ed.) (2020). Qualität der Medien:Jahrbuch 2020. Basel: Schwabe. Retrieved from https://tinyurl.com/36ftmyu4

Fürst, S., Vogler, D., Sörensen, I., Schäfer, M. S., \& Eisenegger, M. (2020). Wirklich irrelevant? Sichtbarkeit und thematische Einordnung der Medien- und Kommunikationswissenschaft in Schweizer Medien [Truly irrelevant? Visibility and thematic contexts of media and communication science in Swiss news coverage]. Publizistik, 65(4), 545-566. https://www.doi. org/10.1007/s11616-020-00601-8

Jarren, O. (2019). Hochschulkommunikation als komplexes Forschungs- und Handlungsfeld - Neue Herausforderungen für die Hochschulen [Communication of higher education institutions as a complex field of research and action - New challenges for higher education institutions]. In B. Fähnrich, J. Metag, S. Post, \& M. S. Schäfer (Eds.), Forschungsfeld Hochschulkommunikation [Research field higher education institution communication] (pp. 417-432). Wiesbaden: Springer VS. https:// www.doi.org/10.1007/978-3-658-224097_19

Kristiansen, S., Schäfer, M. S., \& Lorencez, S. (2016). Science journalists in Switzerland: Results from a survey on professional goals, working conditions, and current changes. Studies in Communication Sciences (SComS), 16(2), 132-140. https:// www.doi.org/10.1016/j.scoms.2016.10.004

Nielsen, R. K. (2018). No one cares what we know: Three responses to the irrelevance of political communication research. Political Communication, 35(1), 145-149. https://doi.org/10.1080/10584609.2017.1 406591

Nielsen, R. K. (2020). Communications research has a lot to offer during the coronavirus crisis: But are we offering it? Retrieved from https://tinyurl.com/Nielsen2020

Pai, M. (2020). Covidization of research: What are the risks? Nature Medicine, 26, 1159. https://www.doi.org/10.1038/s41591-0201015-0

Quandt, T., Boberg, S., Schatto-Eckrodt, T., \& Frischlich, L. (2020). Pandemic news: Facebook pages of mainstream news media and the coronavirus crisis - A computational content analysis. Retrieved from https://arxiv.org/abs/2005.13290 Rauchfleisch, A., Vogler, D., \& Eisenegger, M. (2020). Wie das Coronavirus die Schweizer Twitter-Communitys infizierte. Retrieved from https://www.zora.uzh.ch/id/ eprint/197575/

Robertson-von Trotha, C. Y., \& Muñoz Morcillo, J. (2018). Öffentliche Wissenschaft. Von "Scientific Literacy" zu "Participatory Culture" [Public science: From "scientific literacy" to "participatory culture"]. In S. Selke \& A. Treibel (Eds.), Öffentliche Gesellschaftswissenschaften. Grundlagen, Anwendungsfelder und neue Perspektiven [Public social sciences: Foundations, fields of application and new perspectives] (pp. 43-60). Wiesbaden: Springer VS. https://www.doi.org/10.1007/978-3-65816710-3_3

Robertson-von Trotha, C. Y., \& Muñoz Morcillo, J. (Eds.). (2012). Öffentliche Wissenschaft und Neue Medien. Die Rolle der Web 2.0-Kultur in der Wissenschaftsvermittlung [Public science and new media: The role of Web 2.0 culture in science communication]. Karlsruhe: KIT Scientific Publishing. Retrieved from https://publikationen.bibliothek.kit. edu/1000027942

The Media for Democracy Monitor. (2020a). CoViD-19 and the media: Devastation or renaissance? Retrieved from https:// tinyurl.com/MDM-2020-Covid

The Media for Democracy Monitor. (2020b). Latest press releases. Retrieved from http://euromediagroup.org/mdm/press/

Vogler, D., \& Schäfer, M. S. (2020). Growing influence of university PR on science news coverage? A longitudinal automated content analysis of university media releases and newspaper coverage in Switzerland, 2003-2017. International Journal of Communication, 14, 3143-3164. Retrieved from https://ijoc.org/index.php/ijoc/article/ view/13498 